\title{
Transatlantica
}

Revue d'études américaines. American Studies Journal

\section{Séminaire « Le judaïsme nord-américain » avec Laura Hobson-Faure}

Institut Protestant de Théologie de Paris, 10 février 2014

\section{Sophie Baize-Vézier}

\section{(Q) OpenEdition}

\section{Journals}

\section{Édition électronique}

URL : https://journals.openedition.org/transatlantica/6584

DOI : 10.4000/transatlantica.6584

ISSN : 1765-2766

Éditeur

Association française d'Etudes Américaines (AFEA)

Édition imprimée

Date de publication : 31 décembre 2013

Référence électronique

Sophie Baize-Vézier, « Séminaire « Le judaïsme nord-américain » avec Laura Hobson-Faure », Transatlantica [En ligne], 2 | 2013, mis en ligne le 03 mai 2014, consulté le 05 février 2023. URL : http:// journals.openedition.org/transatlantica/6584; DOI : https://doi.org/10.4000/transatlantica.6584

Ce document a été généré automatiquement le 5 février 2023

\section{(c) (i) () $\Theta$}

Creative Commons - Attribution - Pas d'Utilisation Commerciale - Pas de Modification 4.0 International - CC BY-NC-ND 4.0

https://creativecommons.org/licenses/by-nc-nd/4.0/ 


\section{Séminaire « Le judaïsme nord- américain » avec Laura Hobson-}

\section{Faure}

Institut Protestant de Théologie de Paris, 10 février 2014

\section{Sophie Baize-Vézier}

1 Le réseau Culture et religion dans les pays anglophones (CRPA), fondé par Christiane d'Haussy, rassemble des chercheurs français et britanniques qui s'intéressent au rôle de la religion dans les pays anglophones, que ce soit dans le domaine des arts, de l'histoire, de la littérature, de la sociologie ou de la théologie.

2 Lors du séminaire du 10 février 2014 consacré au judaïsme nord-américain, le CRPA a reçu Laura Hobson-Faure de l'Université de Sorbonne-Nouvelle-Paris III. Elle a présenté son ouvrage consacré aux politiques d'aides juives américaines après la guerre, Un "Plan Marshall » juif: la présence juive américaine en France après la Shoah, 1944-1954, paru en novembre 2013 aux éditions Armand Colin, tiré de sa thèse éponyme soutenue en 2009.

\section{Laura Hobson-Faure, Un « Plan Marshall » juif : la présence juive en France après la Shoah, 1944-1954}

3 L'histoire de la reconstruction des communautés juives après la guerre en France commence à être bien connue, mais ce que l'on ignore souvent, c'est le rôle qu'y a joué la communauté juive américaine, par le biais de l'American Joint Distribution Committee, plus connu en France sous le nom de Joint. Cette instance a ainsi distribué sur une période de dix ans plus de 27 millions de dollars aux Juifs de France et fourni des outils de formation et son savoir-faire en matière de travail social aux organisations juives françaises.

4 Laura Hobson-Faure a choisi de s'intéresser à la décennie qui a suivi la guerre afin de montrer «l'évolution du judaïsme français » sous l'influence américaine. De 1944 à 
1954, les Juifs américains, consacrent $57 \%$ de leurs dons annuels au Joint par le biais de l'United Jewish Appeal (UJA). Cette générosité baisse après 1954, date à laquelle l'argent des réparations allemandes est disponible. C'est aussi le moment où la politique antisémite stalinienne (1953) remet en cause l'aide américaine aux organisations juives d'obédience communiste, telle l'UJRE, l'Union des Juifs pour la Résistance et l'Entraide, fondée en avril 1943.

D'après l'auteur, les Juifs américains n'ont eu de cesse d'aider leurs coreligionnaires européens dès avant la guerre -le Joint a été fondé en 1914 pour secourir les populations juives victimes de la Première Guerre mondiale et des pogroms, et il finance une partie de la résistance juive entre 1942 et 1944. Durant le conflit, beaucoup de Juifs américains se sont enrôlés dans les Forces américaines, et après guerre, c'est tout naturellement qu'ils décident de venir au secours des Juifs rescapés, car la France est perçue comme le point de départ d'une renaissance européenne juive possible. Ce sont des initiatives individuelles, dès 1944, qui sont à l'origine de l'aide américaine: des soldats et des aumôniers juifs décident de venir en aide aux survivants. Cette aide ponctuelle et improvisée trouve un développement centralisé et systématique dans l'action du Joint dès décembre 1944, qui vise à rendre autonomes et autosuffisantes les communautés juives de France. L'effet économique de ces aides financières distribuées par le Joint et d'autres institutions juives à une vingtaine d'organisations juives existantes, quelles que soient leur orientation politique ou religieuse, est indéniable. Elle explique qu'en 1948, lors de la constitution de l'Etat d'Israël, peu de Juifs français choisiront de quitter le pays.

6 Laura Hobson-Faure montre que l'influence américaine a été la plus significative dans le domaine social : le Joint, outre l'aide financière, développe les outils du travail social américains afin de les enseigner et de les adapter à la France. En effet, le système américain s'oppose en tout à l'aide à la française. Celle-ci est essentiellement basée sur le secours individuel ponctuel, sous forme de dons, de distribution alimentaire et vestimentaire, tandis que l'aide américaine qui suit les individus sur la durée est destinée, par le biais de la subvention et de la formation, à la communauté juive dans son ensemble. La politique des organisations juives américaines s'est heurtée aux manières de faire des organisations juives issues de la Résistance, pour lesquelles le secours personnalisé joue un rôle important dans la reconstruction des personnes. Le Joint en particulier est le tenant d'une politique du self-help et du casework qui insiste sur la nécessité d'agir sur la situation sans pathos ni jugement moral, d'analyser les besoins avec des outils scientifiques et non avec l'idée de charité ou de tzedakah (notion de justice et de réparation, utilisée par les Juifs pour décrire la philanthropie). L'idée du Joint est d'utiliser les méthodes de management américaines afin de centraliser la distribution des dons et de fédérer les organisations en supprimant les doublons, afin de gagner en efficacité. Cette idée va petit à petit se développer en France sous l'impulsion du Fonds Social Juif, l'équivalent français de l'UJA crée en 1949. Cette centralisation respecte néanmoins la diversité des groupes, en particulier dans le domaine de l'aide à l'enfance (par le biais de l'OSE, l'Æeuvre de Secours aux Enfants, très active pendant la guerre, qui ouvre encore de nombreuses maisons d'enfants après guerre) à laquelle $50 \%$ de l'aide du Joint est consacrée en 1945. D'autres organisations telles que le Jewish Labor Committee, en lien avec la presse yiddish aux États-Unis, ou le Congrès Juif Mondial qui défend la notion d'une identité ethnique juive spécifique, concurrencent le Joint. 
7 L'influence américaine se fait sentir également, et de manière importante, dans la constitution d'une "communauté juive française ». Les Américains ne comprennent pas la nécessité de la multiplicité d'organisations existantes. La notion de communauté telle qu'elle est perçue aux États-Unis n'existe pas en France. À cette époque, il existe de multiples organisations juives en France, confessionnelles ou non, politiques ou simplement culturelles, qui représentent les Juifs français dans toute leur diversité. La notion de " communauté » juive va émerger petit à petit, grâce au travail coordinateur $\mathrm{du}$ Joint et des organisations américaines, et de son équivalent français, le Fonds Social Juif: en 1949, l'expression "communauté » est utilisée pour la première fois pour " parler de la vie juive en France ».

8 Pour conclure, Laura Hobson-Faure fait remarquer qu'en 1948, le Joint créa une branche en Israël afin d'aider les populations déplacées qui arrivaient nombreuses. Pour les Juifs sionistes qui choisirent de s'installer en Israël, l'Europe était devenue synonyme de mort: tout Juif qui se respecte devait retourner s'installer sur la Terre Promise. Cependant, le Joint ne diminua pas pour autant son aide à la France. Laura HobsonFaure insiste sur le fait que les outils scientifiques américains, enseignés depuis longtemps dans les universités américaines, furent mis au service de l'aide juive américaine en France et modifièrent les notions et le visage du travail social en France. Le judaïsme français fut aussi durablement influencé par la notion américaine de communauté. Il est frappant de noter également que, dans le contexte de la guerre froide, l'aide juive américaine s'est faite indépendamment de toute notion d'appartenance politique.

\section{AUTEUR}

SOPHIE BAIZE-VÉZIER

Université Paris VIII 